\title{
The training experience of nursing educators by virtual training system - results and reflection
}

\author{
Chung, Y.F., Chang, L.C., Cheng, Y.C., Hsu, C.Y., Lin, T.C. \\ Ditmanson Medical Foundation, Chia-Yi Christian Hospital, Taiwan
}

\section{Background:}

The Virtual Training System (VTS) is already used in the field of medicine. However, the using on nursing training is rare. Here, we investigate the training experience of the nursing educators by a qualitative analysis.

\section{Method:}

The VTS (on Clinical Decision Making) was used in our hospital since June, 2020. The training classes of VTS were provided for both medical and nursing educators. An anonymous survey with 5 openended questions containing operative experience and suggestion were asked after the training classes. A qualitative analysis was performed through the feedback of the nursing educators.

\section{Results:}

A total of 9 nursing educators from the department of internal medicine participated the training class on December 18, 2020. The training time was 1.5 hours. After the training class, all nursing educators agreed to answer the questionnaire survey. The qualitative analysis revealed that the VTS provided a safe environment for better understanding of history taking, physical examination and differential diagnosis. In addition, the nursing educators considered that teaching nursing trainees to respond to clinical practice in class is quite important.

\section{Conclusion:}

The VTS provides a safe environment for nursing training. Guiding the trainees to deal with clinic situations in the classroom is very important.

Keywords: Virtual Training, Clinical Skills 